\title{
Modeling the Effect of Engine Parameters on Engine Temperature during ICE Operations.
}

\section{Motey Festus and Dr. Essel Ben Hagan}

Nomenclature

ICE Internal Combustion Engine

\section{Abstract}

Increasing manufacturing of more complex internal combustion engines has led to application of sophisificated computer programs in automobile industry for production and servicing. Some of these applications are modeling and simulation. These applications are also applied to heat transfer with reference to the objective of this article. A maximum of thirty three percent (33\%) of total heat generated is transferred to coolant to be blown away. During operations of internal combustion engines, factors such as age, fuel type, pressure, environmental temperature, road nature, among others influenced rate of heat transfer within ICEs.Internal combustion engines are design in such a way that waste combustible gases are channeled through exhaust system. Components of the exhaust system are designed in such a way to withstand failures, stresses, vibrations and impact. In these engines, convection, radiation and conduction are modes of heat transfer through metal components and fluid. Sources of heat generation in these engines are friction within piston - cylinder liner compact and internal fuel combustion. Thus, internal combustion is the process of burning fuel with oxidizer exclusively in combustion chamber to produce heat energy. The methodology adopted involves modeling and simulation of heat equations. Thus, objectively these equations are analyzed to predict how these parameters will decrease heat generations. Graphical results obtained from applying this methodology indicate temperature reduction.

Key words: Manifold; Exhaust; Heat transfer; Fuel; Combustion.

\section{INTRODUCTION}

Researching into operations of internal combustion engines is receiving much attention or is on the rise. More developed methods or approaches such as modeling and simulation have been applied for these researches. All components as well as processes of internal combustion engines needed to be analyzed through modeling and simulation for efficient functioning.Ferguson and Kirkpatrick, (2001). Thus, mathematical equations which represent models of such components, systems and processes were built for analysis such as state estimation, control strategies, predictive accuracy, control techniques, fault diagnostics, among others. Approximately twenty five percent $(25 \%)$ to thirty three percent $(33 \%)$ of the heat produced during internal combustion is transferred to coolant. Furthermore, heat generated from air - fuel mixture ignition and combustion is absorbed or transferred to cooling fluid in motion in the engine. 
This absorptionmode may vary with referenceto operating conditions such as number of piston rings, number of pistons, piston diameter, weight of connecting rod and engine temperature.Agrawal, Singh, Sinha and Shukla, (2004);Hahn and Ozisik, (2012). Cylinder wall, cylinder bore, cylinder head, exhaust valve seals and lubricant characteristics are some of engine components through which generated heat is transferred. Normally, modes of heat transfer in internal combustion engines or vehicle engines are conduction, convection and radiation. Forced convection accompanied by minor radiation are modes of heat transfer from combustible gases to metal components within internal combustion engines. Conduction is the major mode of heat transfer from cylinder metal to lubricant channels within automobile engines.

Another source of heat generation within internal combustion engines is friction between inner liner of metal cylinder and piston as well as piston rings. This effect of heating due to friction is reduced by application of recommended lubricants. In internal combustion engines, transfer of heat may be unsteady, nonlinear and non - uniform which are problemsthat are still been researched into. Liquid fossil fuel or underground fractionally distilled crude oil used by ICEs are gasoline or petrol and diesel.Dembroski, (2002);Sumin, (2013).Vapourized fossil fuel burnt in combination with an oxidizer or oxygen exclusively in a tight combustion chamber is referred to as internal combustion. Processes of internal combustion occurs intermittently resulting to chemical energy content of fuel been converted to heat. This heat energy is subsequently converted to mechanical energy and transferred through powertrain for automobile motion. This energy provides force on automobile components such as shafts, bearings, nozzles, alternators, pistons, connecting rods, valves, among others. Fuel tanks, connecting lines, fuel pumps, filters, fuel meter and atomizer are some basic components of internal combustion engine fuel system. Devices such as carburetors and injectors are used to spray fine fuel droplets into filtered air or gas for combustion in internal combustion chamber. The objective of this research is to model and simulate the effect of some engine parameters on engine temperature when ICE is operating.Finol and Robinson, (2006); Chan, Ordys, Volkov and Duran, (2013); Mirko, (2014).

\section{REVIEWED LITERATURE}

Fresh air - fuel mixture enters the internal combustion chamber through inlet duct. At intake manifold, the mixture splits before directed into cylinders. Port walls as well as upper surface of valve head form a convergent geometry for experiencing changing velocity of internal flows.Sanli, Ozsezen, Killicasian and Canakci, (2007);Ge, Chen and Sun, (2008). Heat transfer properties are associated with fluid movement around cylinder as well as coefficient of heat transfer vibration. Designs of various cylinder heads are such that they must withstand failures, heat flux, velocity of gases impact as well as ensuring accurate temperature distribution. Shapes of exhaust and intake valves are practically the same but differ in type of flow that passes through them. Andrew, Robert and Jhon, (2002);Ebrahimi, (2009);Janowski, Shayler, Robinson and Goodman, (2011).Thus, exhaust valve heads experience push due to high velocity of exhaust gas leading to formation of stagnation region. Also, high turbulence, high impingement, high heat transfer, high thermal loads as well as high thermal stresses are experienced by exhaust system, particularly by exhaust valve. Increasing temperature gradients may occur and soot form is removed by 
oxidation. Turbulence as well as forced heat convection at exhaust valve due to exhaust gases also occurs.Carlos, (2008); Arcoumanis and Kamimoto, (2009).

\section{METHODOLOGY}

The models or equations consist of empirical and algebraic equations which are implemented. Combustion processes in cylinder are represented by mathematical models. Relatively, modeling and simulation are less time consuming as well as less expensive as compared to experimental and other computational methods. Thus, these models provide simulation as well as modeling tools. This methodology will serve as tools and diagnostic algorithms for control engineers.Arnold and Polking, (2004); Lan and Srinivasan, (2009). Also, this methodology can be used to analyze linkage between angular speed of crankshaft, net engine torque, inertial variation of crankshaft assembly as well as piston pin offset. Furthermore, this methodology is used for modeling and simulation of thermodynamic cyclic vibrations, exhaust manifold heat transfer, mass flow rate as well as friction. Coombes, Hunk, Lipsman, Osborn and Stuck, (2000). Air - fuel flow rates, engine load and vibrational crankshaft speed are also factors considered for this methodology. Modeling of these models or equations involved writing programs in matlab and using values from tables of previous literature. Simulation involves opening simulink window and picking relevant blocks from simulink libraries. Inputs from tables of values in previous literature are inserted into respective blocks and these blocks are linked by signal lines. Bayrakar and Durgun, (2003).

\section{EQUATIONS FOR MODELING}

The following equations given below account for characteristics of heat transfer through exhaust manifold in internal combustion engines.

\section{Burn Fraction Variation}

Equation 1

$$
X_{b}(\theta)=1-\exp \cdot\left[-a\left(\frac{\theta-\theta^{n}}{\theta^{d}}\right)\right]
$$

Source: Karkamkar, (2013).

This equation above is a model for determining the fraction of unburnt fuel.

Where

$X_{b}(\theta)=$ burn fraction as a function of crank angle

$\theta=$ crank angle

$\theta_{s}=$ spark timing

$\theta^{d}=$ duration of heat release

$n=$ Weibe form factor

$a=$ Weibe efficiency factor

$$
a=5
$$




$$
n=3
$$

$$
\theta_{s}=-p i / a
$$

\section{Cylinder Average Heat Flow}

Equation 2

$$
\stackrel{*}{Q}_{g, w}=f\left(b m e p, \eta_{I C E}, T w\right)
$$

Source: Kanne, 2000.

The equation (110) one hundred and ten above represents the sub - model for cycle average heat flow.

Where

$\stackrel{*}{Q}_{g, w}=$ Heat flow in cylinder wall

$f=$ Fuel quantity

$\eta_{I C E}=$ Rotational speed of internal combustion engine

$T w=$ Torque in cylinder wall

Density of Inlet

Engine External Cooling

Equation 3

$$
\stackrel{*}{Q}_{r, \text { in }}=\left(T_{r, \text { in }}-T_{r, \text { out }}\right) \times C_{p c} \times \stackrel{*}{m}
$$

Source: Kanne, 2000.

The equation (113) one hundred and thirteen above represents a sub - model for engine external cooling

(flow of heat to heat exchanger).

Where:

$\stackrel{*}{Q}$, in $=$ Heat flow of coolant entering the radiator

$T_{r, \text { in }}=$ Temperature of coolant entering the radiator

$T_{r, \text { out }}=$ Temperature of coolant leaving the radiator

$C_{p c}=$ Heat capacity of coolant

$\stackrel{*}{m_{r}}=$ Mass flow rate of radiator

Equation 115

Source: Kanne, (2000)

$$
\frac{d X_{b}}{d \theta}=\left(1-X_{b}\right) \frac{a n Q_{\text {in }}}{\theta_{d}}\left(\frac{\theta-\theta_{s}}{\theta_{d}}\right)^{n-1}
$$

The equation (115) one hundred and fifthteen above is a model for change of fuel burnt fraction with respect to crank angle. 


\section{Where}

$Q_{\text {in }}=$ heat supplied by fuel

$X_{b}=$ burnt fraction at crank angle

$\mathrm{n}=$ Weibe force factor

$\mathrm{a}=$ Weibe efficiency factor

$\theta=$ crank angle

$\theta_{s}=$ spark timing

$\theta_{d}=$ duration of speed

Heat Transfer

Equation 116

$$
\stackrel{*}{Q_{c, e b}}=z_{c} \times \alpha_{c} \times A_{e b} \times\left(T_{e n g, m}-T_{e b}\right)
$$

Source: Kanne, 2000.

The equation (116) one hundred and sixteen above is a sub - model for heat transfer between the coolant and engine block.

Where:

$z_{c}=$ Number of cylinder

$\alpha_{c}=$ Coolant heat transfer coefficient

$A_{e b}=$ Area of engine block

$T_{\text {eng }, m}=$ Temperature of engine cylinder wall

$T_{e b}=$ Temperature of engine block.

Inlet or Intake Temperature of Fluid

Equation 118

$$
T_{i p}=T_{o f}\left[1+1 / 2(\gamma-1) M^{2}\right]^{-1 / \gamma-1}
$$

Source: Clive (2007)

The above equation is a model for temperature of inlet liquid fuel.

Where

$T_{i p}=$ Inlet temperature of fluid

$T_{o f}=$ Temperature of fluid at $293 \mathrm{k}$ or $0^{\circ} \mathrm{C}$

$M=$ match number $=0.1$

$\gamma=1.4$

\section{MODELING OF EQUATIONS}

Matlab Program for Equation (109) One Hundred and Nine

OSPARK TIMING ON COMBUSTION

○BURN FRACTION VARIATION

functionburnfractionvariation ( $\mathrm{xb}$ )

$\circ \mathrm{xb}=1-\exp \left(-\mathrm{a}^{*}(\right.$ theta - thetas/thetad)^n) 


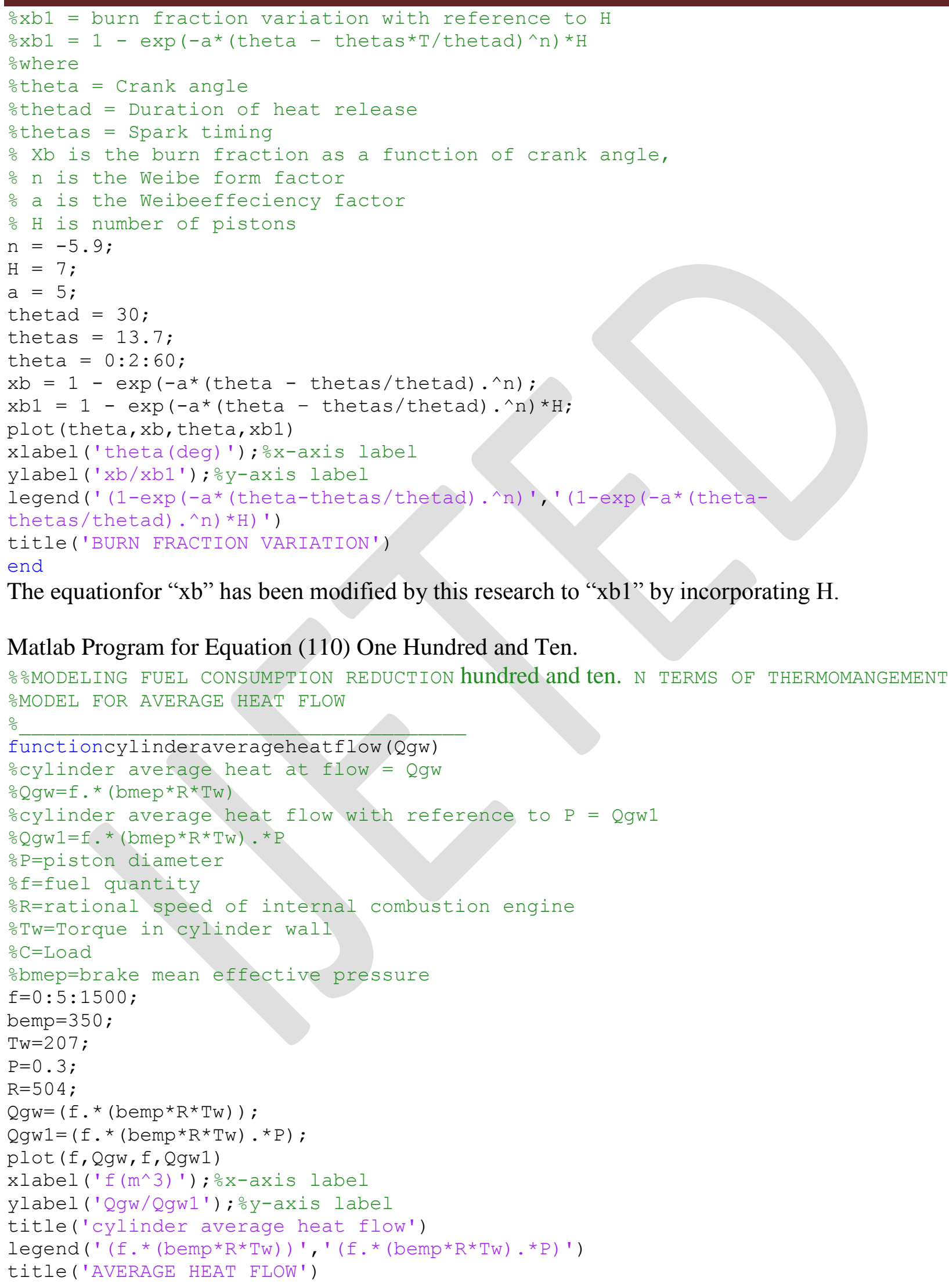


The equation for "Qgw" was analyzed by previous author and modified by incorporating P to form "Qgw".

Matlab Program for Equation (113) One Hundred and Thirteen.

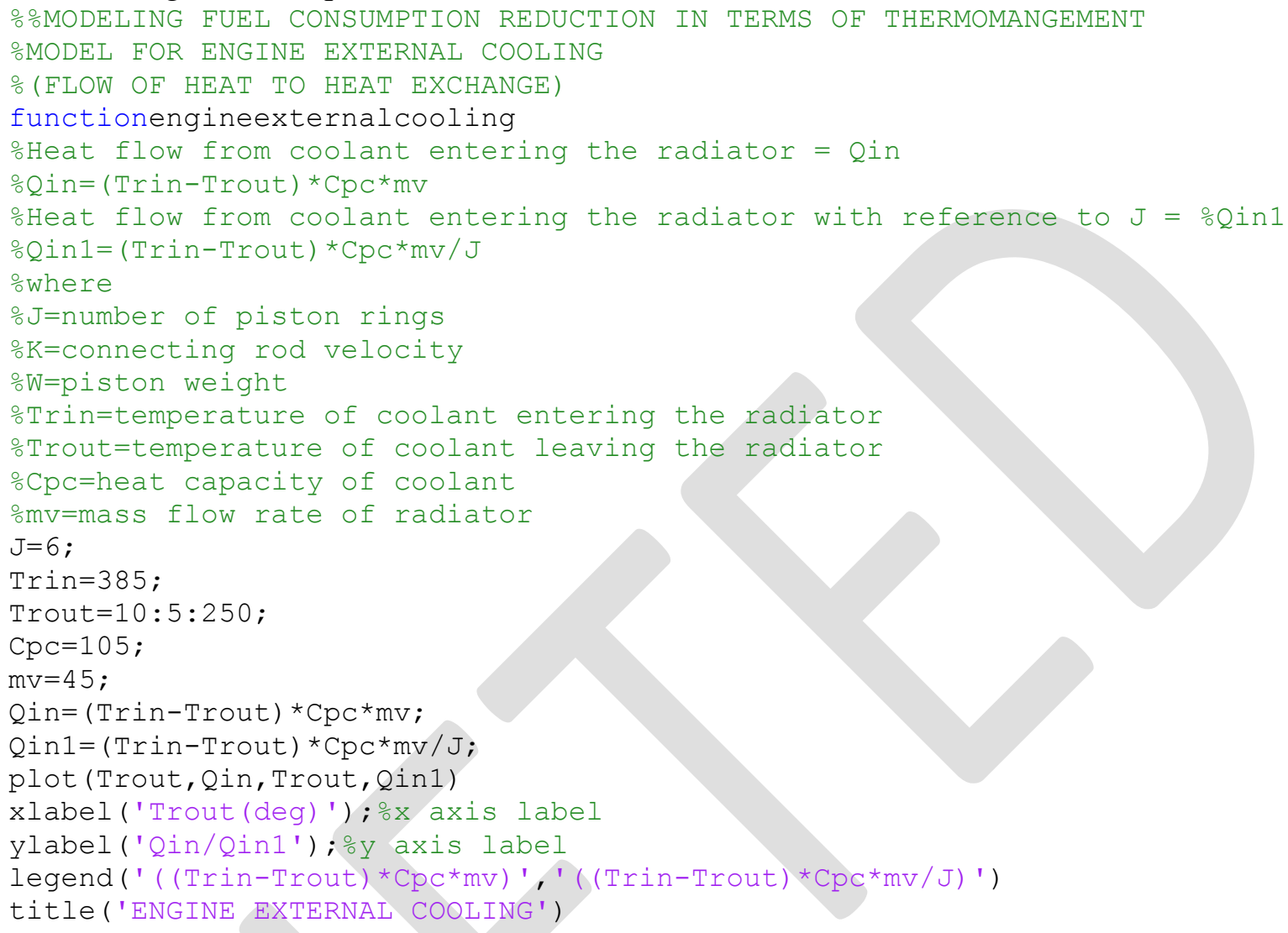

This research has remodeled equation "Qin" to equation "Qin1" by incorporation of J into Qin.

Matlab Program for Equation (115) One Hundred and Fifteen

ㅇPTIMIZATION OF CONTROL LAW FOR AIR FUEL RATIO

HEAT RELEASE RATE

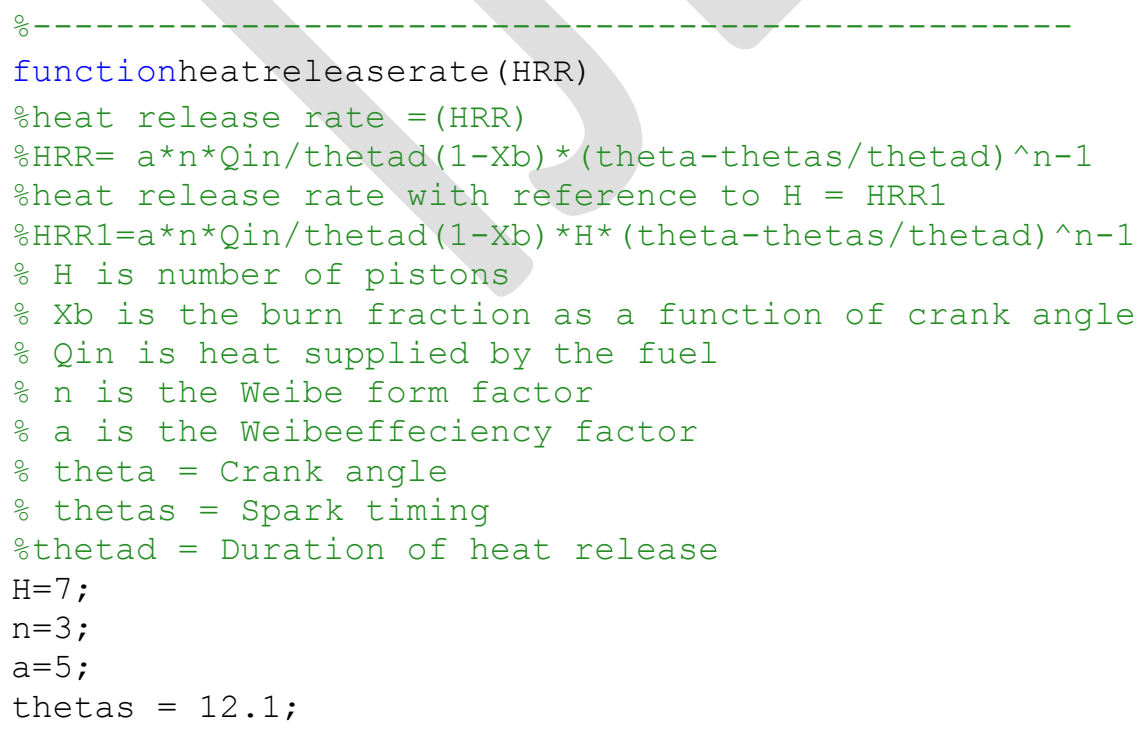




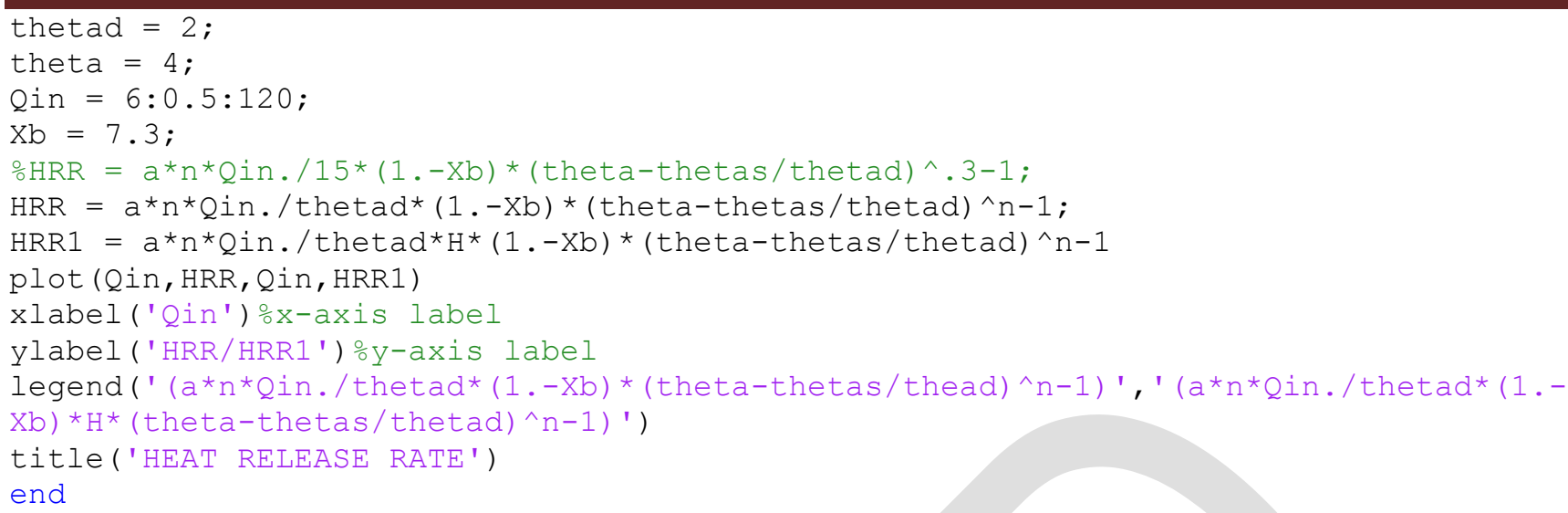

Equation "HRR" has been modeled by the previous author but this research has also remodeled it to equation "HHR1" by incorporation of $\mathrm{H}$.

\section{Matlab Program for Equation (116) One Hundred and Sixteen \\ 음IING FUEL CONSUMPTION REDUCTION IN TERMS OF THERMOMANGEMENT OMODEL FOR HEAT TRANSFER BETWEEN THE COOLANT AND ENGINE BLOCK}

\section{functionheattransfer}

oHeat transfer between the coolant and engine block = htb

$\circ h t b=z c *(x c * A e b) *($ Tengm-Teb $)$

oHeat ransfer between coolant and engine block with reference to $\mathrm{N}=\mathrm{htb}$

$\circ \mathrm{htb} 1=\mathrm{zC}^{*}(\mathrm{xc} * \mathrm{Aeb}) *($ Tengm $-\mathrm{Teb}) * \mathrm{~N}$

$\circ \mathrm{N}=$ connecting rod weight

$\% \mathrm{zc}=$ number of cycle

\% $\mathrm{xc}=$ coolant heat transfer coefficient

$\circ$ Aeb $=$ area of engine block

oTengm = tmperature of engine inlet

oTeb = temperature of engine block

$\mathrm{N}=3.5$;

$\mathrm{zC}=1: 0.5: 160$;

$\mathrm{Aeb}=32$;

Tengm=76;

$\mathrm{xC}=38$;

$\mathrm{Tel}=58$;

$\mathrm{htb}=\mathrm{zc} \cdot{ }^{*}(\mathrm{xc} * \mathrm{Aeb})$ * (Tengm-Teb) ;

$h t b 1=z c . *(x c * A e b) *($ Tengm $-\mathrm{Teb}) * N$;

plot (zc, htb, zc, htbl)

xlabel ('zC'); $\circ$ x-axis label

ylabel ('htb/htbl'); $\%$-axis label

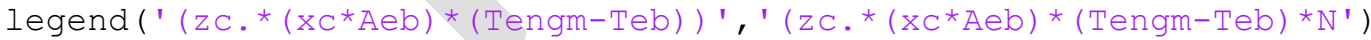

title('HEAT TRANSEER BETWEEN THE COOLANT AND ENGINE BLOCK')

end

Analyzing equation "htb" was done by the previous author but has been remodeled by this research to form equation "htbl" through the incorporation of $\mathrm{N}$.

\section{Matlab Program for Equation (118) One Hundred and Eighteen}

\section{oFLUID CHARATERISTICS MODELING IN ICE(MODELS)}

\% INLET TEMPARATURE OF FLUID

functioninlettemparatureoffluid (ITOF)

o Inlet temperature of fluid = ITOF 


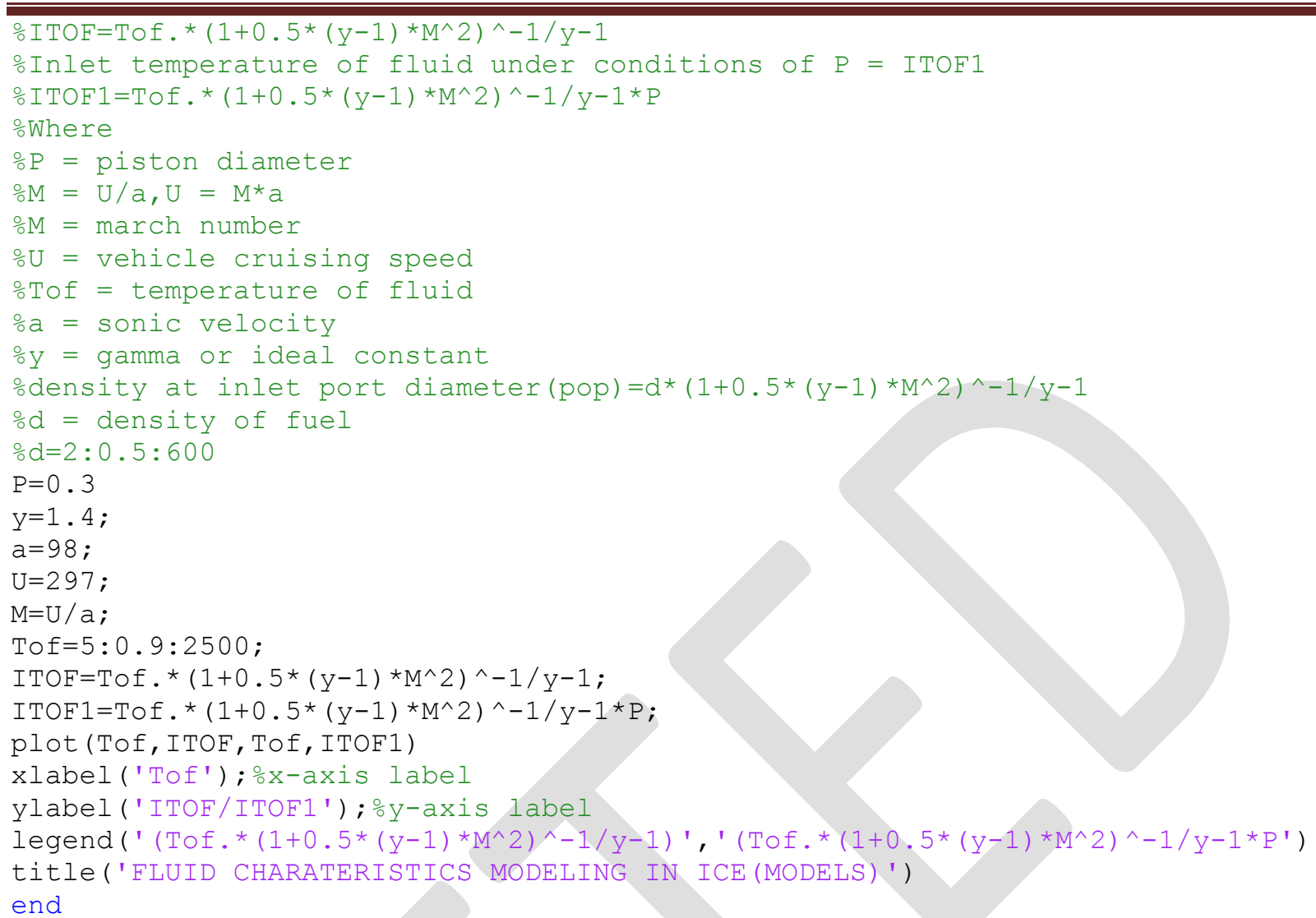

The equation "ITOF" has been remodeled by this research to form equation "ITOF1" by incorporating P.

\section{SIMULATION OF EQUATIONS}

Simulation scheme for equation 109

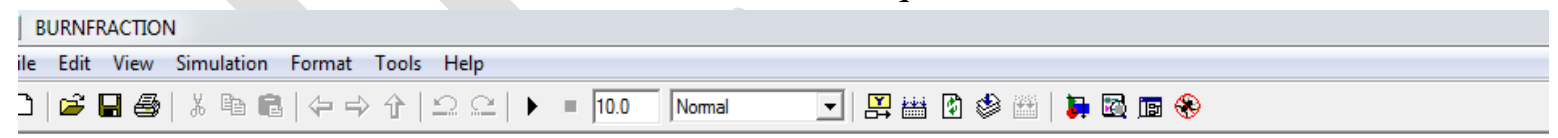

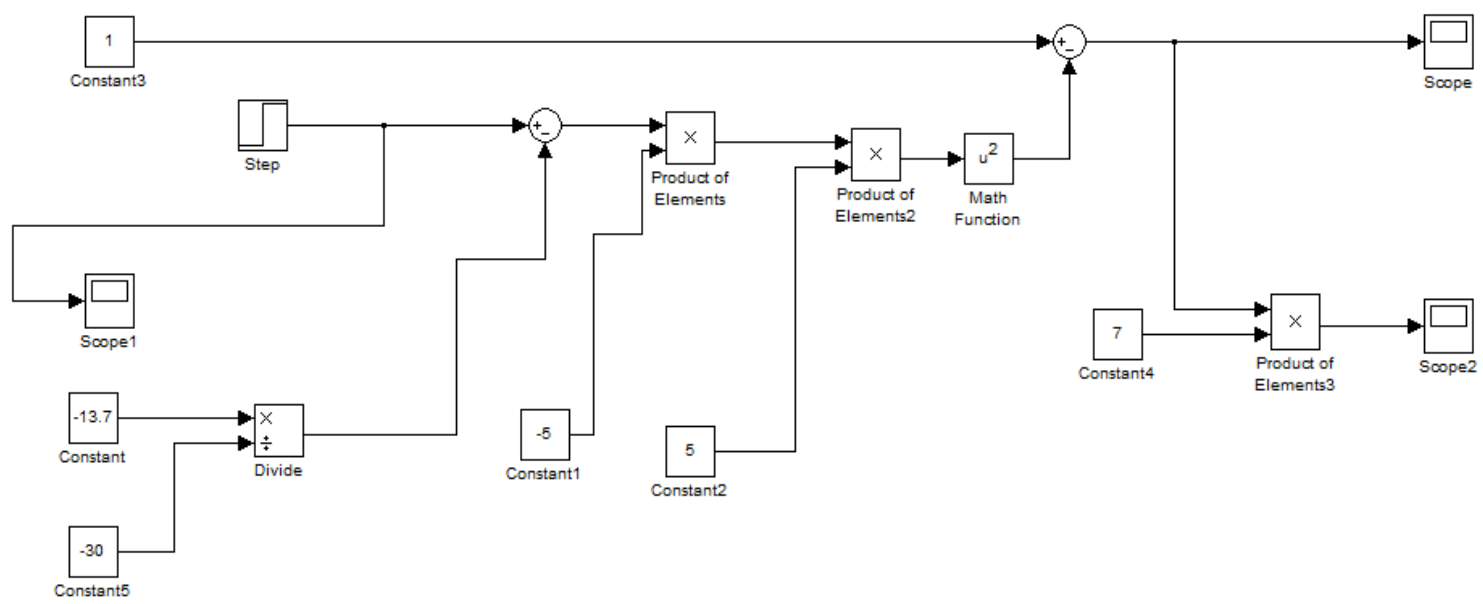




\section{Simulation scheme for equation 110}

\section{MODELFORAVERAGEHIT}

File Edit View Simulation Format Tools Help

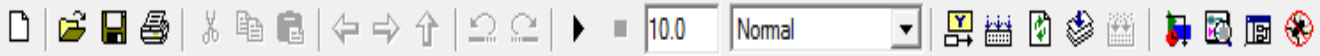

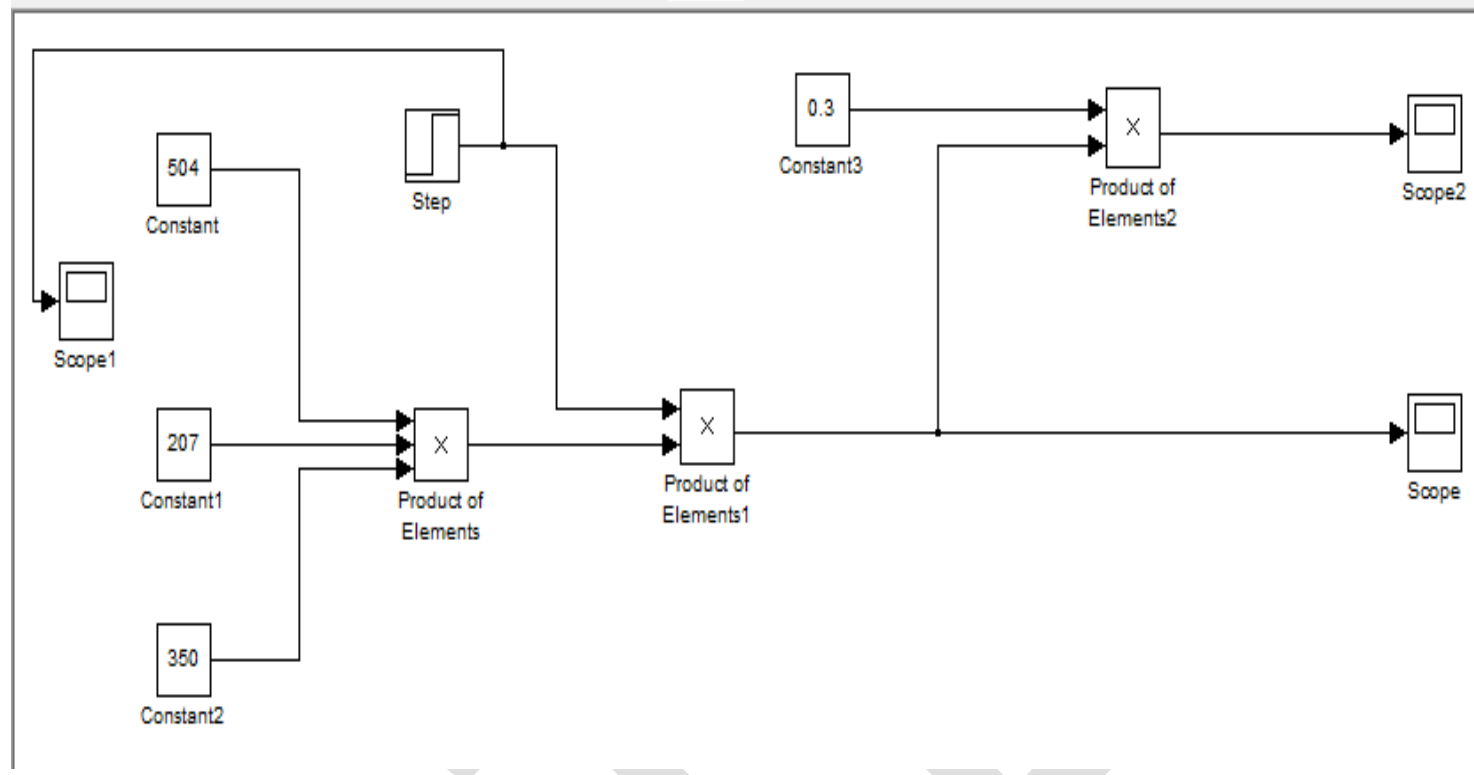

Simulation scheme for equation 113

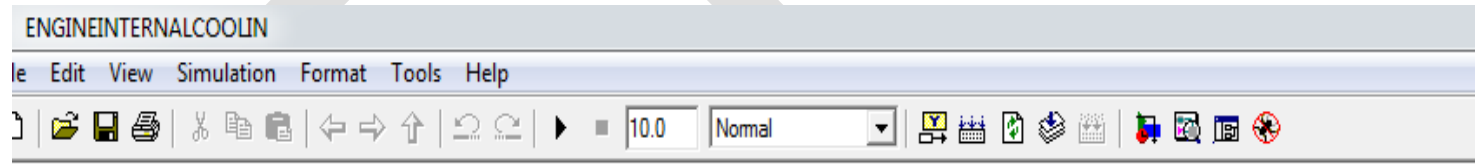

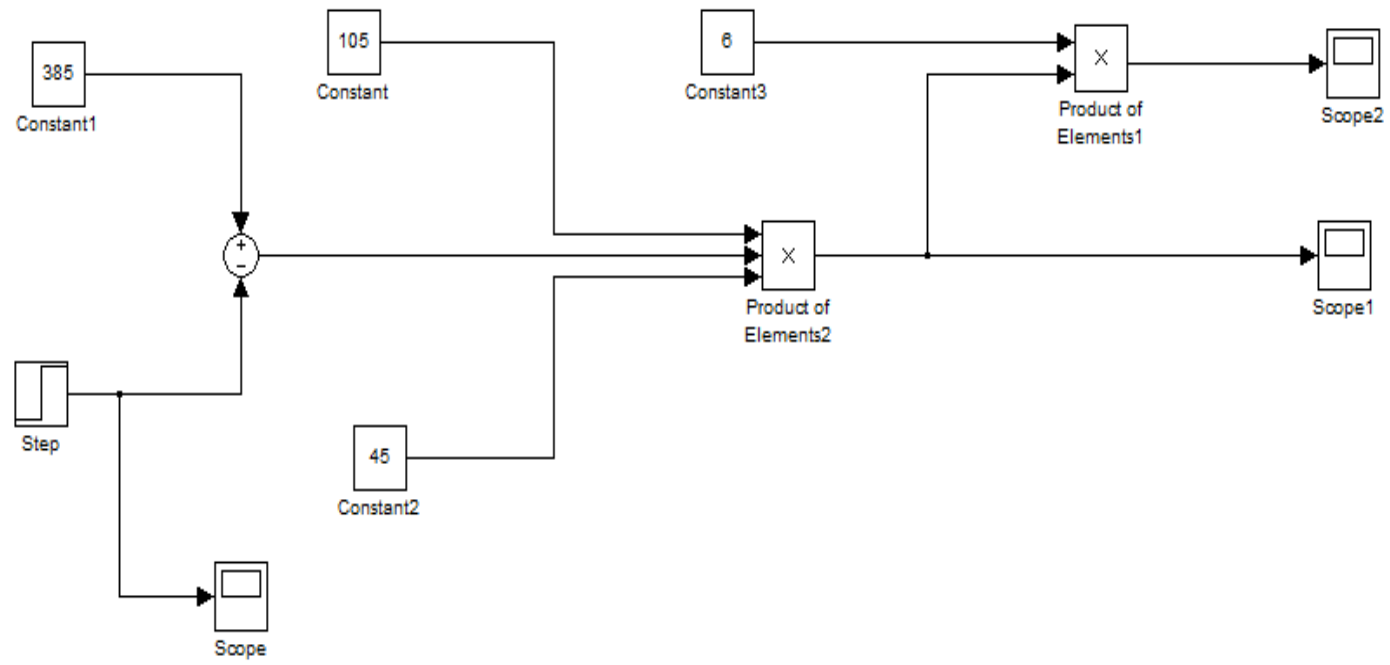




\section{Simulation scheme for equation 115}
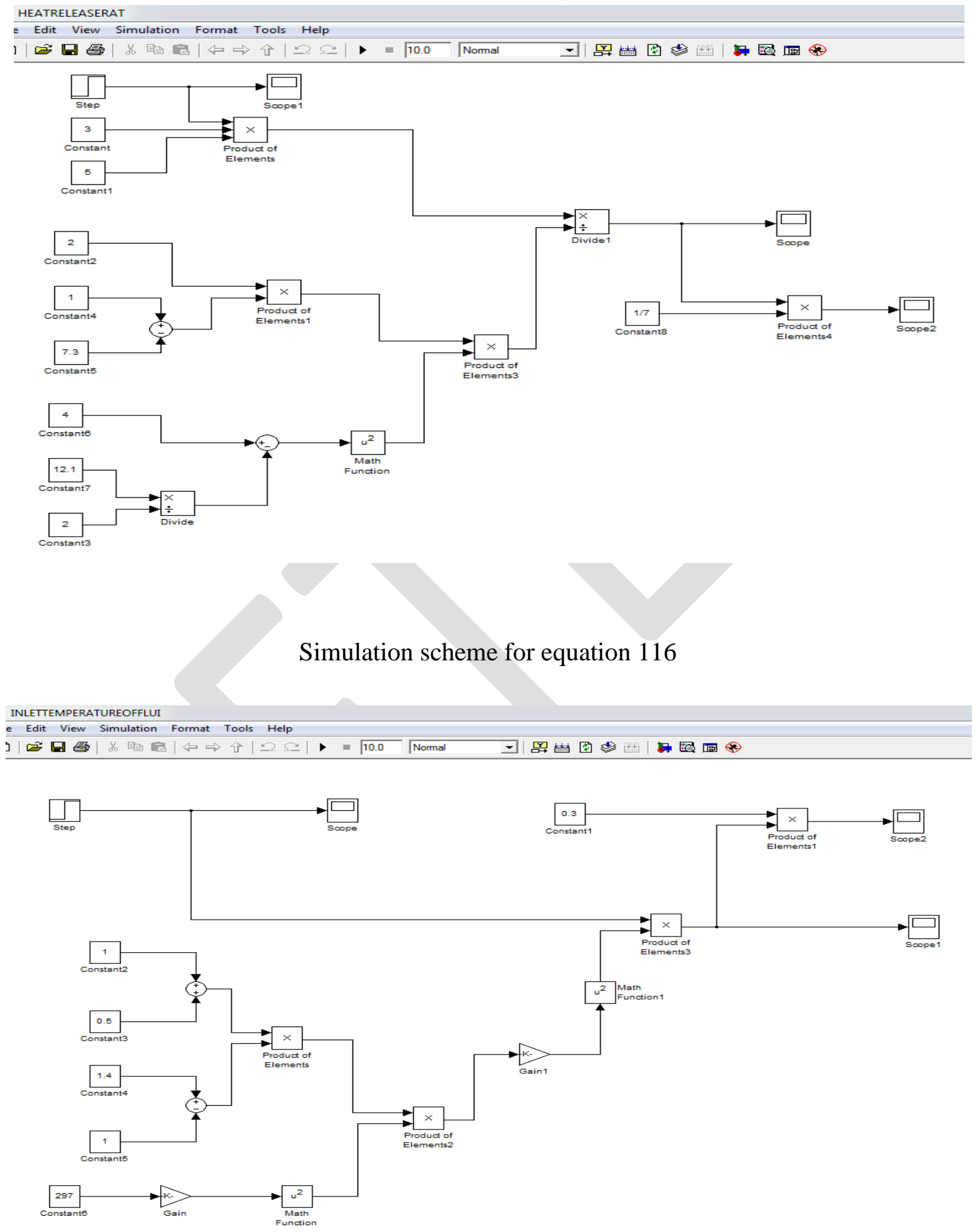
DOI : https://dx.doi.org/10.26808/rs.ed.i8v1.05

International Journal of Emerging Trends in Engineering and Development Available online on http://www.rspublication.com/ijeted/ijeted_index.htm

\section{Simulation scheme for equation 118}
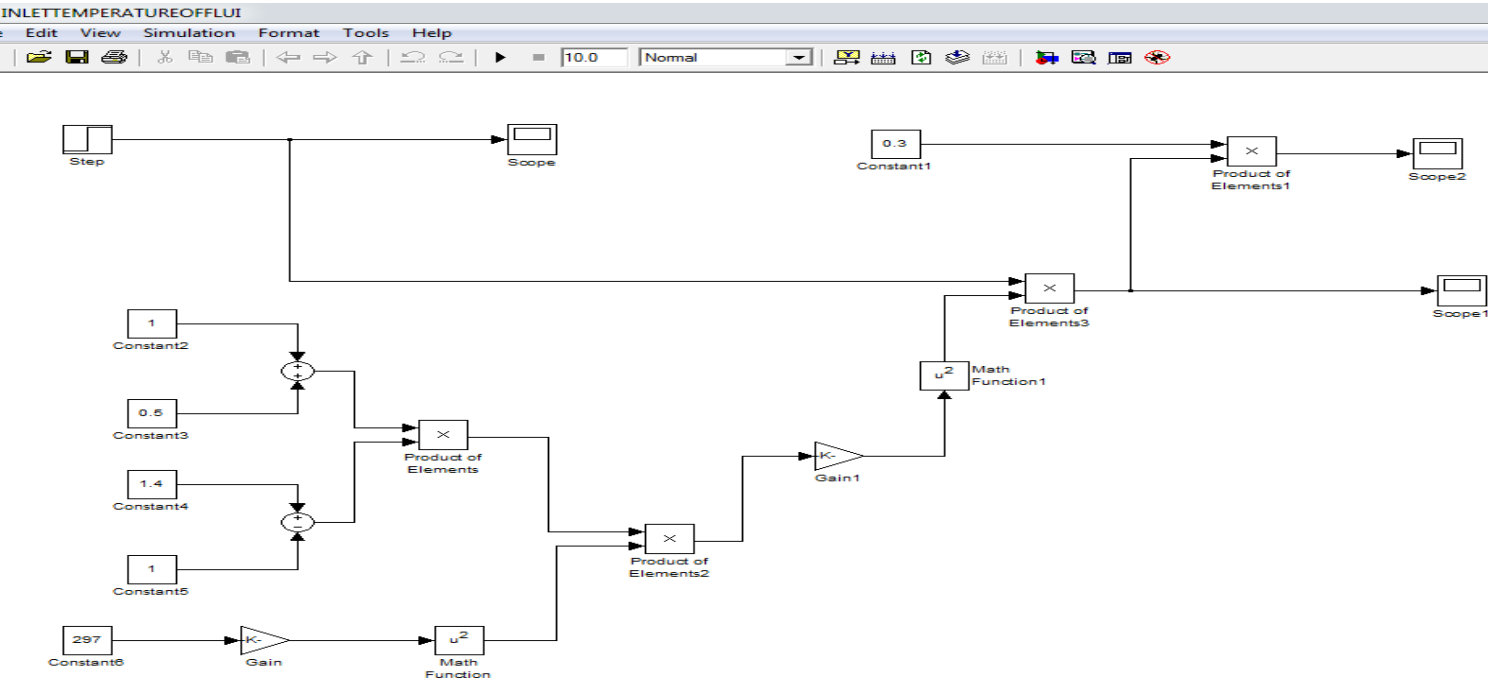

MODELINGRESULTS

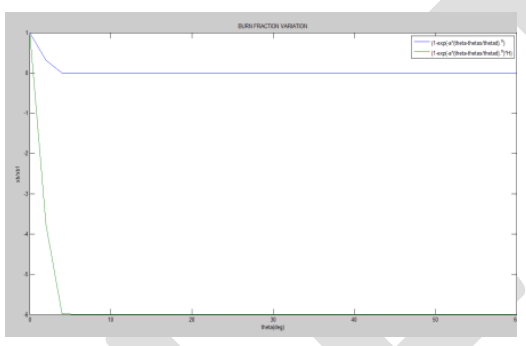

Modeling results for equation 109

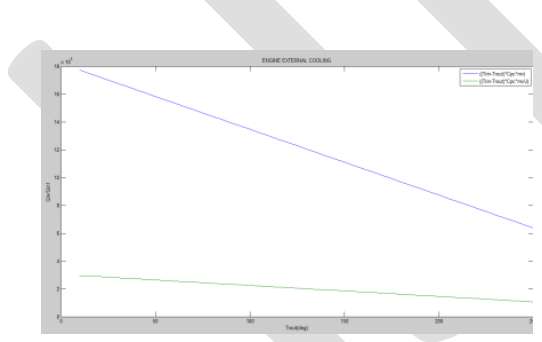

Modeling results for equation 113

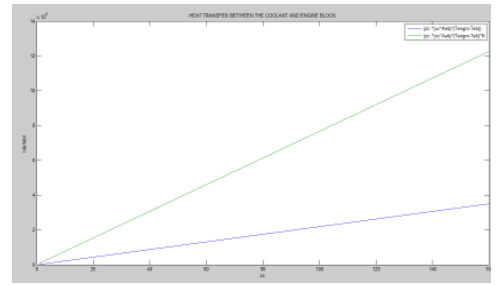

Modeling results for equation 116

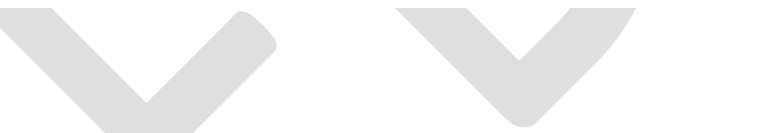

Modeling results for equation 110

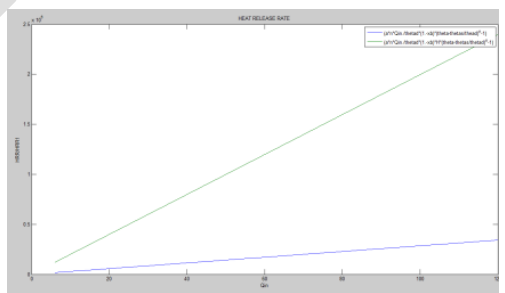

Modeling results for equation 115

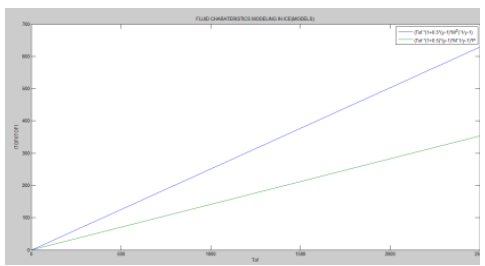

Modeling results for equation 118 


\section{SIMULATION RESULTS}

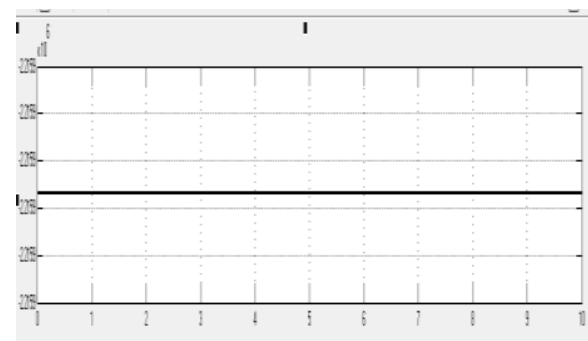

Simulation result i for equation 109

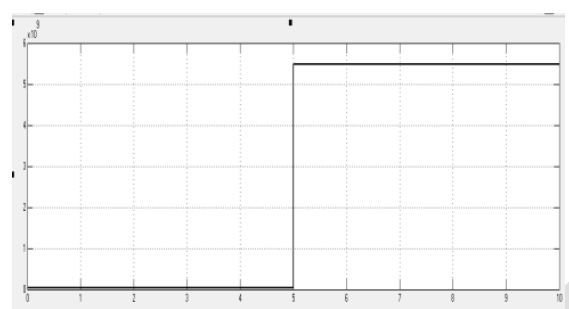

Simulation result i for equation 110

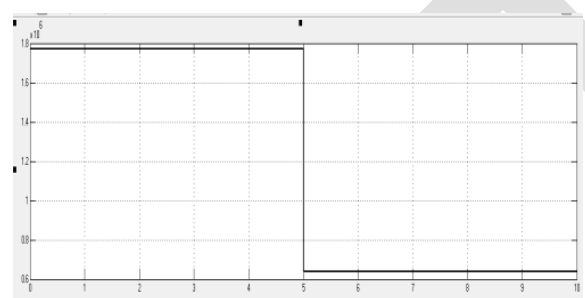

Simulation result i for equation 113

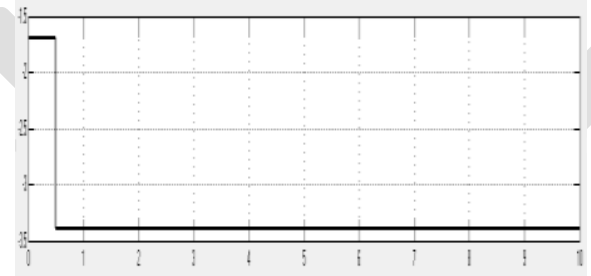

Simulation result i for equation 115

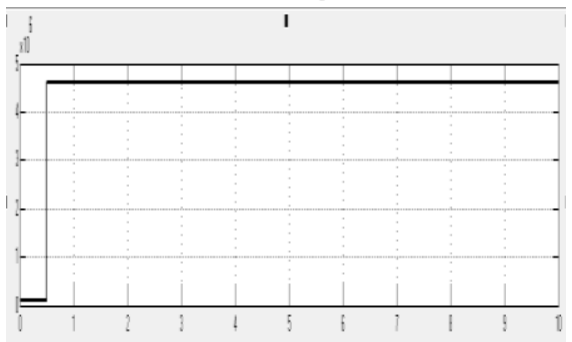

Simulation result i for equation 116

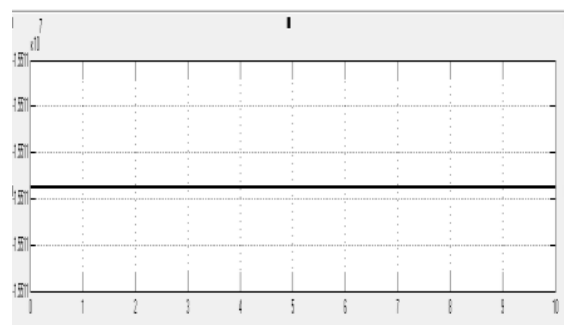

Simulation result ii for equation 109

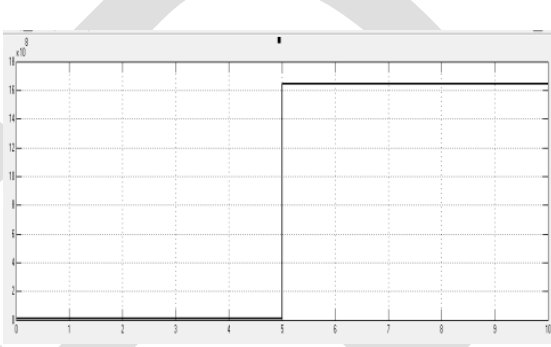

Simulation result ii for equation 110

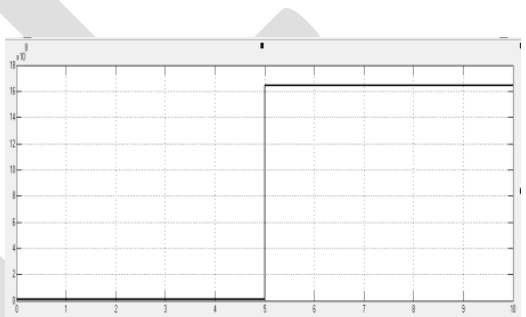

Simulation result ii for equation 113

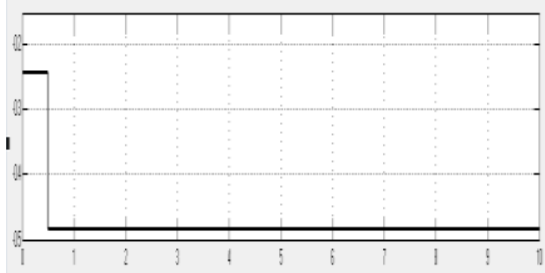

Simulation result ii for equation 115

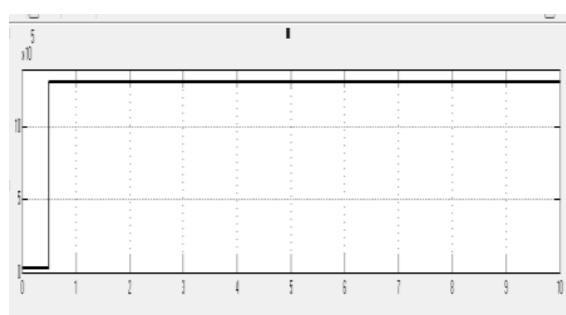

Simulation result ii for equation 116 


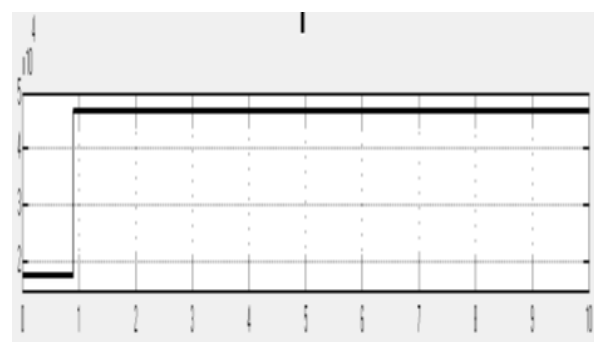

Simulation result i for equation 118

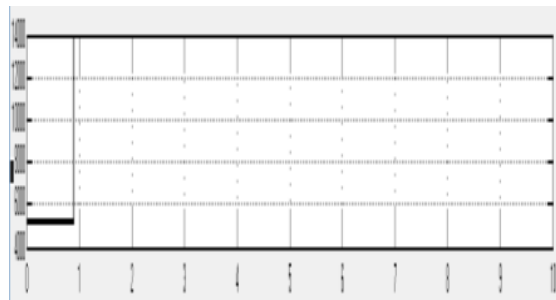

Simulation result ii for equation 118

\section{ANALYSIS OF RESULTS}

The modeling results contain two coloured lines. Thus, blue lines are for modeling results of previous authors' equations and green lines are for modelingresults after incorporation of these parameters. These lines are analyzed to observe variations due to influence of ICE parameters that were incorporated into previous equations. Thus, graphically, these green lines will show relative reductions or increases with respect to variables to be measured. Also, simulation results ii indicates increases or decreases after incorporation of these parameters before simulation. Modeling results of equations 109 and 118 show reductions in fuel consumption and inlet temperature of fuel respectively. Thus, the parameters have reduction effects after their incorporations. Results for remodeling of equations 110, 113, 115 and 116 after incorporation of these parameters shown by the green lines that heat flow, heat released as well as heat transferred have increased. Simulation results ii for equations 109 and 118 indicated reductions in rate of fuel consumption and inlet fuel temperature. After incorporation of these parameters, simulation results ii of equations $110,113,115$ and 116 show reductions in temperature.

\section{CONCLUSION AND RECOMMENDATION.}

All graphical results indicated that incorporation of these parameters show reduction effect on temperature and rate of fuel consumption. However, more research must be done using other methods and parameters.

\section{RFERENCES.}

- Agrawal, A. K., Singh, S. K., Sinha, S. and Shukla, M. K. (2004). “Effect of EGR on the Exhaust Gas Temperature and Exhaust Capacity in Compression Ignition Engines".Sadhana, 29(3), pp. 275 - 284.

- Andrew, N., Robert, S. and Jhon, C. A. (2002).HDTS $2^{\text {nd }}$ Edition. McGraw - Hill (Publisher).

- Arcoumanis, C. and Kamimoto, I. (2009). “Flow and Combustion in Reciprocating Engines".Springler - Verlag, Berlin Heidelberg.

- Arnold, D. and Polking, J. C. (2004).Ordinary Differential Equation using MATLAB.Prentice Hall (Publisher).

- Bayrakar, H. and Durgun, O. (2003)."Mathematical Modeling of Spark Ignition Engine and Simulations Engine Cycle”. Energy Source, 25(5), pp. 439 - 455.

- Carlos, A. F. P. (2008). Heat Transfer Investigations in a Modern Diesel Engine.PhD Thesis.Department of Mechanical Engineering, University of Bath.

- Chan, K. Y., Ordys, A., Volkov, K. and Duran, O. (2013).“Comparison of Engine Simulation Software for Development of Control System”.Modeling and Simulation in Engineering (Publisher). 
- Clive, L. (2007). "One Dimentional Modeling of an Internal Combustion Engine".Mekanikfordjupning.

- Coombes, K. R., Hunk, B. R., LipsmanR. L., Osborn, J. E. and Stuck, G. J. (2000). Differential Equation with MATLAB.John Willey and Sons (Publisher).

- Dembroski, T. T. (2002). "Piston Heat Transfer in the Crankcase at High Engine Speed". Journal for Society Automotive Engineers, $01-3350$.

- Ebrahimi, R. (2009). "Thermodynamic Simulation of Performance of an Endoreversible Dual Cycle with Variable Specific Heat Ratio of Working Fluid". Journal of America Science, 5(5), pp. 175 180.

- Ferguson, C. R. and Kirkpatrick, A. T. (2001).Internal Combustion Engine.Applied Thermo Sciences, $2^{\text {nd }}$ Edition.John Willey and Sons (Publisher). NY, USA.

- Finol, C. A. and Robinson, A. (2006). "Thermal Profile of a Modern Passenger Car Diesel Engine". Journal for Society of Automotive Engineers, $01-3409$.

- Ge, Y., Chen, L. and Sun, F. (2008). "Finite Time Thermodynamic Modeling and Analysis of an Irreversible Otto Cycle".Applied Energy Journal, 85(7), pp. 618624.

- Hahn, D. W. and Ozisik, M. N. (2012).Heat Conduction ( $3^{\text {rd }}$ Edition). John Willey and Sons Incorporated (Publisher).

- Janowski, P., Shayler, P. U., Robinson, S. and Goodman, M. (2011). "The Effectiveness of Heating Parts of the Powertrain to Improve Vehicle Fuel Economy during Warm - up". VTMS 10.

- Kanne, E. C. (2000). Engine Thermomangement for Fuel Combustion Reduction.Doctoral Thesis, Swiss Federal Institute of Technology, Zurich.

- Karkamkar, A. (2013). "Effect of Spark Timing on Combustion Process of SI Engines Using Matlab".International Journal of Computer Applications.

- Lan, K. T. and Srinivasan, K. (2009). "Influences of Free Steam Conditions on Vehicle Thermal Management - An Analytical Study". Journal for Society of Automotive Engineers, 01 - 1152.

- Mirko, B. (2014). Principles of Heat Transfer in Internal Combustion Engines from the Modeling Standpoint.PhD Thesis University of Tecnology, Gothenburg, Sweden.

- Sanli, A., Ozsezen, A. N., Killicasian, I. and Canakci, M. (2007). "The Influence of Engine Speed and Load on the Heat Transfer between Gases and In- Cylinder Walls at Fired and Motored Conditions of an IDIDiesel Engines". Applied Thermal Engineering (Publisher).

- Sumin, M. (2013). Heat Measurement InsideCombustion Engine with Gradient Heat Flux Sensor. Lappeenranta University of Technology. 